\title{
The Problems of Statistical Analysis of Interregional Markets
}

\author{
Panasyuk M.V.
}

Latypov R.A.

\author{
Kazan Federal University, Kazan Institute of Plekhanov Russian University of Economics, Russia
}

\section{Doi:10.5901/mjss.2014.v5n18p327}

\begin{abstract}
s
The paper describes the author's approach to the statistical analysis of structure of interregional trade flows and interregional commodity markets. The analysis of functioning of modern interregional markets on base of the three categories of goods and services is carried out. Role of improving market statistics and information support as the main factors of development of interregional markets is discussed. Main methodical and organizational problems of statistical analysis of their trade flows are determined. The scheme of analysis of interregional trade flows is demonstrated.
\end{abstract}

Keywords: statistical analysis, interregional trade flow, interregional commodity market, market regulations.

\section{Introduction}

Interregional trade-economic relations and trade flows circulating between economic entities of the national economy in the process of production, distribution, exchange and consumption of different goods are integrating basis of national economic space [6]. Economic space of state includes the conditions and prerequisites for the functioning of national economic system and its regional markets. These conditions form, first of all, the processes of regional division of labor and elements of economic potential of regions that constitute the material and technical basis of regional reproduction process as well as the capacity and the consumption structure of regional economics.

A distinctive feature of the current state of goods markets of countries of the world is faster growth of interregional exchange of products in comparison with growth of production. Objective reasons for this process are: increased competition in goods and services markets, growing demand in fuel and energy resources, deepening specialization in production and, consequently, expanding production cooperation.

In these conditions significantly increases the role of operative, detailed statistical information on interregional trade flows of the country, which is the determining factor of a choice of effective administrative and management decisions at all levels of the regional economy. This refers to not only to regional and federal public authorities, but also to commercial firms for which such information is key-note when choosing a competitive market strategy and marketing tactics.

Pressing economic problems that are urgent in the field of interregional economic relations in the period of Russia's transition to market system has led to the development of the Comprehensive Program of Infrastructural Development of Commodity Markets, which in June 1998 was approved by the decree of the Government of the Russian Federation. The main purpose of the Program [3] was the formation of system of institutions and conditions of their functioning, providing interrelation between structural elements of commodity markets of the country and promoting free movement of goods between regions of the Russian Federation through the development of an overall development strategy for medium-term and long-term prospects. One of its main tasks was to establish effective communication for commodity markets' functioning, including the creation of national and regional information and marketing centers, the adaptation of information-analytical networks of strategic marketing, etc., and the formation of the system of state monitoring of commodity markets and mechanisms for distribution of information and advertising.

However, unfortunately, even after expiration of the mentioned period of this Program, the problems of providing effective tools for the analysis of interregional commodity markets and their infrastructural elements are far from being solved, which hampers effective interregional merchandising, increases product prices and reduces competitiveness of manufacturers.

It is also important to develop the appropriate theoretical approach and to improve methodology of statistical analysis of interregional economic relations and structure of trade flows within the country. 


\section{Problem Formulation}

Modern economic theory [1] is considering economy of any nation mainly in the form of single national market, which is, in particular, the aggregate of interconnected regional markets of the country. Main macroeconomic instruments of its quantitative analysis are the system of national accounting, various indicators and industrial indexes. However, huge territory of the Russia, maldistribution of production factors, determines conceptually the appropriateness of individualization and analysis not only regional, but interregional markets. Development of the concept of interregional markets leads to the formulation of a number of methodological problems of statistical analysis of interregional trade flows, including:

- Formation of the general principles of the organization of supervision and analysis of interregional economic relations;

- Development of methods and systems of indicators for the study of state and dynamics of interregional trade flows;

- Development of statistical tools for the study of the competitive environment, objects and subjects of the interregional markets.

It is clear that interregional markets of the country are characterized by a limited number of suppliers (producers) and consumers (buyers) of the particular product, but at the same time, by numerous trade flows which have huge volume and great variety of directions. Basic business entities forming interregional economic flows are large industrial and agricultural enterprises and organizations, government bodies and regional administration [2]. Therefore, major regional markets of the country objectively have often monopolistic or oligopolistic structure with significant barriers to entrance to and to exit from them, so they are characterized by imperfect competition. However, despite the fact that the interregional market should be, in conditions of developed market relations, self-organizing and self-regulating system, it cannot exist without special organization and regulation by the state as social institution, representing not only the current economic, but long-range national interests of the country [3,5, and 7$]$.

With standpoint of expediency of state regulation of regional economic activities, as well as of rational specialization of real sector of national economics, goods and services as commercial activities on interregional markets could be divided into three categories:

- Goods and services of strategic importance that providing international trade and economic (hence national) security of the country;

- Goods and services which production is technologically efficient in framework of regional cooperation with the subsequent interregional commodity exchange;

- Goods and services which are suitable to produce and consume independently within their own regions.

Obviously, the subject of focused attention of Federal Government bodies will be an interregional commodity exchange of the first and second categories, and for regional authorities - goods and services of the second and third categories. In the first case forms of macroeconomic analysis and the system of national accounting (SNA) dominate, in the second - methods of regional analysis [1], i.e. the level of regional trade markets

The choice of the measures for regulation interregional economic relations and estimation of efficiency of their application is possible only on the basis of fairly complete aggregated information, characterizing the level and dynamics of interregional goods distribution, expenditures of different means of transport and manufacturing enterprises, etc. In the framework of national policy of promoting economic growth and development of interregional competition, disaggregated information is increasingly important, because it allows analyzing information about specific trade markets and about their market insiders. Creation of conditions for development of free information interchange within and between regions is the key factor for successful development of interregional markets, stimulation market demand for them and overcoming their relative economic isolation.

Unfortunately, the economic statistics of interregional market remains underdeveloped as in effect of usually low solvency of potential customers, and because of narrow range of services of consultancy firms. The demand not only in general summary information on the functioning of the interregional markets, but very specific data on certain commodity components is growing objectively. General data of the state statistics are too general from the point of view of an individual enterprise or firm.

"Private" brunch statistics in the context of highly disaggregated brunches is collected mainly in various regional associations, regional representative offices, Chambers of Commerce and Industry and business associations. Usually they do not pursue commercial goals, but this approach allows them, in some ways, to clarify, complement, and sometimes to double-check the official state statistics. Main instruments of such statistical surveys are different enquiriesinquiries of the trade market insiders at all stages of goods distribution: manufacture - wholesale layer - retail trade. 
"Private" statistics, as a general rule, loses the state statistics through the coverage of target statistical population, but at the same time it is in many cases even more detailed and operational.

In the enlarged range of products [3], recommended by the Federal State Statistics Service of the Russian Federation for analysis and forecasting of development of commodity markets, there is about 200 product names, which are distributed among 10 industrial markets of fuel and energy resources, iron and steel industry products, etc. For the purposes of discussion analysis of interregional markets on the basis of this information it is required to exclude multiple counting of intermediate commodities from the gross regional product by detachment of first order goods from the mentioned range of products.

Besides, serious research is needed in the field of study of interregional flows of black economy as a separate entity of statistical analysis in the framework of system of national accounting, including intraregional level. In this connection, it should be noted that due to the specificity of manifestations of concealed and informal activities at all stages of economic cycle and also because of differences in the information, it is still not possible to use a generic method of calculation of shadow (black) economy. Unfortunately, there are only general approaches that are recommended for calculations currently. The use of expert estimations is effectively enough when it is necessary to give the qualitative characteristics or to identify the general trend of development of the studied phenomena.

In our opinion, to estimate the missing parameters of one or another regional system you can use the same characteristics of other similar system. For example, survey findings, obtained in one of the regions, could be used, with certain qualifications, for calculations of similar indicators in other regions which have similar set of conditions. In case of time series interruption, missing data can be obtained by interpolation or extrapolation. For calculations of concealed and informal production in some industries and regions it could be used collecting of not direct, but indirect information. Regular additional sample observations could play an important role in this process.

In our opinion, the best method for calculation of unknown parameters of formal and informal (concealed) activities in interregional markets of the country is the balance method of analyzing incoming and outgoing trade flows, as it is based [8] on comparison of interrelated indicators of regional reproduction process. Mismatching of the quantitative characteristics of certain indicators allows hypothesizing about causes of discrepancies and amount of necessary corrections for each region and the whole country [4]. Obviously, the quality of analysis results obtained in application of the interregional balance of commodity-money flows will be the higher the greater is number of interconnected regional parameters, which we associate with each other.

\section{Main Process Stages of Statistical Analysis of Interregional Trade Flows and Markets and their Content}

Taking into account the abovementioned theoretical arguments and practical problems, the statistical analysis of interregional trade flows of a country, in our opinion, structurally should include the implementation of a sequence of stages revealing general situation on interregional markets of a country, and also including calculation of the efficiency of each macro-logistical channel, analysis of territorial and institutional structure of purchase and sale for each region, assessment of interregional competition, opportunities of interregional commodity turnover growth, etc. We came to conclusion that such type of analysis should contain five main stages.

The first stage includes the characteristics of GRP growth dynamics and dynamics of industrial production in each region, changes in productive capacity, dynamics of import and export of consumer and capital goods with other regions, including goods turnover which was realized within the framework of international economic relations. The growth of efficiency of regional economy may be indirectly indicated by increase in volume of sales per capita (per worker), and increase in trade space letting, etc.

The second stage is to characterize the structure of imports and exports of goods, and also the structure of exports and imports for each region by various logistical channels. For the analysis of interregional relations it is necessary to compare the data on dynamics of purchases and sales of surveyed type of goods for each logistical channel of a specific territory and abroad with data about the level of regional prices of separate channel.

The third stage includes the study of basic purchase channels of each given commodity. To justify the most rational scheme of interregional goods distribution it is required to analyze market supplies and structure of the purchase prices. Price analysis should be linked to the nature of competition on regional markets of the country and problems of supplies, storage bases and forms of settlements. In this aspect it is necessary to analyze sales for each logistical channel.

The fourth stage envisages the calculation of interregional indexes of concentration as a sales exposure of individual types of goods of the largest enterprises of the region to the total volume of national sales. The concentration index of purchases of goods is determined similarly. These data should be compared with estimates of level of 
interregional price-related competition. In particular, according to the sampled population of enterprises that are specific to each individual logistical channel you can perform a statistical analysis of prices, growth rates of purchases and sales, and level of labor efficiency in all regions. The coefficients of interregional merchantability and regression of price level on different factors can show the importance of antimonopoly policy.

The fifth stage envisages grouping of participants of interregional markets by estimations of changes of production output, consumption and price level, as well as in the institutional structure of channels of goods distribution and competitive advantages of each subject. Indicators, which give a comprehensive estimating of dynamics and closeness of interregional economic relations, must be aggregated in a separate bloc. The most important are the indicators of pay balance and trade balance of each region of the country.

The analysis of interregional trade and economic relations with taking into account their dynamics for a certain period, promotes main findings about the importance and dynamics of trade flows. It helps to highlight transport schemes and channels of goods distribution prevailing in interregional markets, to estimate the factors and the degree of competitiveness of enterprises in various regions. The segmentation of interregional markets of the country, which is a combination of statistical grouping with statistical verification of assumptions about inhomogeneity of obtained groups, is realized on its basis. The segmentation can be carried out according to consumers of goods, according to parameters of products and to consumers of goods simultaneously, as well as according to major competitors, economic regions, and Federal Districts.

Central to the analysis of statistical data about interregional trade flows of the country should be the study of spatial schemes of goods distribution based on the study of distribution (buying) channels of the largest manufacturers (buyers) from different regions. In this connection, the analysis of survey results of interregional markets of the country should be conducted on the basis of special tables, which are focused on analysis of aggregated data for each region and characterizing a situation on surveyed enterprises at different stages of distribution in whole.

\section{Conclusion}

Thus, currently there is an objective necessity of improving the scheme for collection, analysis and dissemination of statistical information about interregional markets. It requires revision of the system of statistical indicators and improvement of the statistical register subject to requirements of analysis of state of interregional markets of the country. It also requires more in-depth study of logistic schemes of goods distribution, degree of satisfaction of demand for separate kinds of goods, and receiving operative information about goods supply. Information about the interregional economic relations of the country should be based not only on the current statistical reporting of large enterprises in different regions, but also on regular special surveys and market surveys. Solving of mentioned problems in the Russia should be based on a thorough study of the experience of developed countries and its adaptation to conditions of the country.

\section{References}

Granberg A.G. (1993) The national and regional commodity markets in the USSR: Trends and contradictions of the transition period, Papers in Regional Science, 72 (1), 3-23

Hammer N. (2010) Cross-border cooperation under asymmetry: The case of an interregional trade union council, European Journal of Industrial Relations, 16 (4), 351-367

Mishchenko A.P., Latypov R.A. The management of interregional economic relations, Kazan: KGFEl Publ., 2005, 189pp.

Mur J., Trivez F.J. (1996) Dynamic modeling of interregional economic activity: An application to the Spanish labour market, Papers in Regional Science, 75 (4), 463-481

Puga D. (1999) The rise and fall of regional inequalities, European Economic Review, 43 (2), 303-334

Panasyuk M.V., Bagautdinova N.G, Safiullin L.N. and Novenkova A.Z. (2013) Territorial Approach to Solving the Region Strategic Management Problems, World Applied Sciences Journal, 27 (Economics, Management and Finance), 149-153

Rodríguez-Pose A. (2012) Trade and Regional Inequality, Economic Geography, 88(2), 109-136.

Uglitskikh O.N., Klishina, J.E. (2013) Modeling interregional inter-branch relations as an element of interaction between the branches of the agroindustrial complex, Middle East Journal of Scientific Research, 13 (Special Issue), 183-190 